\title{
Synthesis of soluble and autophotosensitive hyperbranched polyimides with good optical properties and thermal properties
}

\author{
Changwei Liu, Daming Wang, Wei Wang, Yongyao Song, Yan Li, Hongwei Zhou, Chunhai Chen and \\ Xiaogang Zhao \\ A series of autophotosensitive hyperbranched polyimides based on a new triamine, 1,3,5-tri(3-aminophenoxy-4'-benzoyl) \\ benzene (TABB), various aromatic dianhydride monomers, and endcapped with ortho-alkyl aniline was synthesized by two-step \\ chemical imidization methods. UV-vis spectra indicated high optical transparency of the hyperbranched polymer (HBPI) films \\ with a UV-vis absorption edge of $342-353 \mathrm{~nm}$. The spin-coated films of HBPIs presented a minimum birefringence value as low \\ as 0.0026 at $650 \mathrm{~nm}$ and low dielectric constants of 2.74-3.09 (at $1 \mathrm{MHz}$ ). The HBPI films also showed high glass-transition \\ temperatures between 190 and $238^{\circ} \mathrm{C}$, good thermal stabilities with $5 \mathrm{wt} \%$ loss temperatures ranged from 506 to $525^{\circ} \mathrm{C}$ and \\ excellent organosolubilities even in acetone and chloroform. Photolithographic property of the polymer was examined by UV \\ exposure. SEM analysis revealed that highly resolved pattern with a line width of $20 \mu \mathrm{m}$ were obtained. \\ Polymer Journal (2013) 45, 318-325; doi:10.1038/pj.2012.134; published online 4 July 2012
}

Keywords: autophotosensitive; hyperbranched; polyimides; synthesis

\section{INTRODUCTION}

In recent years, dendritic macromolecules have drawn considerable attention because of their unique physical and chemical properties, such as low viscosity, high solubility and a large number of terminal functional groups, caused by the highly branched structure. ${ }^{1-4}$ These dendritic macromolecules are mainly classified into dendrimers and hyperbranched polymers (HBPIs). Monodisperse, well-defined and perfectly branched dendrimers are prepared by a stepwise growth procedure, but the stepwise nature of their synthesis makes large-scale production difficult as the growth of a single generation requires several reactions and purification steps. ${ }^{5}$ However, irregularly branched and polydisperse HBPIs are synthesized by a one-pot polymerization, which makes the large-scale synthesis possible at a reasonable cost. HBPIs are thought to have physical properties similar to those of dendrimers and can be used to replace dendrimers in industrial applications.

Since Kim and Webster ${ }^{6}$ reported the hyperbranched polyphenylenes in the early 1990s, interest in HBPIs has been increasing at an amazing rate. Studies in this field cover the theory, synthesis, structural characterization and properties and investigations into potential applications. ${ }^{2,5}$ The special structures of less entangled polymer chains and a large number of terminal reactive groups of HBPIs, in combination with their low viscosity and excellent solubility in organic solvents, is an excellent prerequisite for their use in new applications, such as optical and electronic materials, ${ }^{7-10}$ polymer electrolytes, nanotechnology, ${ }^{11-14}$ and other high-tech areas. ${ }^{15-18}$

The applications of HBPIs as photosensitive materials seem to be very promising. Compared with linear polymers, HBPIs with low chain entanglement and compact molecular chains may offer some advantages for those attempting to pattern feature sizes that are on the order of the molecular dimensions. In addition, the high functionality of the peripheral photosensitive groups is expected to produce high sensitivity toward exposure. Kakimoto et al. ${ }^{19}$ reported a positive-type photosensitive polyamide based on the branched polyamides with low degree of branching and S-DNQ as a photosensitive compound; it showed a sensitivity of $140 \mathrm{~mJ} \mathrm{~cm}^{-2}$ under $436 \mathrm{~nm}$ (g-line) light exposure. Tang et al. ${ }^{20}$ described a new route to hyperbranched polyarylenes (hb-PAs) that was functionality tolerant and regioselective. Using base-catalyzed alkyne polycyclization, hb-PAs with carbonyl functionality were synthesized and exhibited high photosensitivity and generate photopatterns with nanometer resolutions. The hb-poly(amic acid)s (PAAs) exhibited high sensitivities $\left(D^{0.5}=50-180 \mathrm{~mJ} \mathrm{~cm}^{-2}\right)$ and well-resolved patterns, with line widths of 1.0 and $1.5 \mu \mathrm{m}$ were readily obtained when the film exposed to a UV dose of $1 \mathrm{~J} \mathrm{~cm}^{-2}$.

Photosensitive polyimides (PSPIs) have been widely used in the semiconductor industry as interlevel insulators, buffer coat materials, $\alpha$-ray shielding layers, and so on, because of their high mechanical properties, excellent thermal stability and relatively low dielectric 
constants. $^{21-24}$ The commercially available PSPIs usually consist of (PAA), where crosslinking sites are introduced into PAAs. However, in most cases with PAAs, high-temperature thermal treatment is required to convert the patterns of PAAs to those of corresponding PIs, which generally have poor solubility. This high-temperature process is not applicable to electronic devices because the great shrinkage in the patterned films on account of the removal of small molecules during thermal cyclization and small-molecule initiator. To remedy these problems, fully imidized organo-soluble auto-PSPIs are currently desired in the industry. Recently, Pfeifer et al. ${ }^{25}$ developed a negative working PI system combining a certain degree of thermal stability, and good image resolution based on $3,3^{\prime}, 4,4^{\prime}$-benzophenonetetracarboxylic dianhydride (BTDA) and ortho-alkyl aromatic diamines. They also mentioned that meta-substituents significantly reduced the photosensitivity. This result was associated with the intramolecular CT affected by the $N$-phenyl conformation. Chen et al. ${ }^{26}$ reported the first synthesis of autophotosensitive hyperbranched polyimides with good organosolubilities and excellent thermal stabilities. They also used BTDA as dianhydride, and terminally by ortho-alkyl anilines to yield autophotosensitivity and generate photopatterns. However, Higuchi et al. ${ }^{27}$ determined the low quantum yield of crosslinking for an analogous negative PI derived from BTDA, and bis (4-amino-3ethylphenyl)-methane may be related to the CT interactions in wholly aromatic PIs. The lower electron-acceptability of dianhydrides and lower electron-donatability diamines, caused the higher LUMO and lower HOMO energies, may lead to weaken both intra- and intermolecular CT interactions, respectively. ${ }^{28}$ Therefore, we have focused on the synthesis of higher autophotosensitivity aromatic PIs while maintaining lower CT interactions.

In this study, new trifunctional diamine with benzophenone carbonyl group was prepared to obtain a series of soluble autophotosensitive hyperbranched polyimides. Their thermal properties, mechanical properties, dielectric constant and optical properties were also investigated. It was characterized that the prepared PHPIs exhibited low birefringences in the range of $0.0026-0.0085$, good organosolubilities, good transmittances higher than $82 \%$ at $800 \mathrm{~nm}$, and excellent thermal and mechanical properties.

\section{EXPERIMENTAL PROCEDURE}

\section{Materials}

Hydrochloric acid $(\mathrm{HCl})$, aluminum chloride $\left(\mathrm{AlCl}_{3}\right)$, potassium carbonate $\left(\mathrm{K}_{2} \mathrm{CO}_{3}\right)$, fluorobenzene, 3-aminophenol, 2,6-dimethylaniline and 1,3,5-benzenetricarbonyl trichloride were purchased from commercial sources and used as received. Benzophenonetetracarboxylic dianhydride (BTDA, Sigma-Aldrich, St Louis, MO, USA), 4,4'-(4,4'-isopropylidenediphenoxy)bis(phthalic anhydride) (BPADA, Sigma-Aldrich), 4,4'-(hexafluoroisopropylidene)diphthalic anhydride (6FDA, Manac Corporation, Kyoto, Japan) were dried in vacuum oven at $180^{\circ} \mathrm{C}$ for $4 \mathrm{~h}$. $N, N$-dimethylformamide (DMF), $N, N$-dimethylacetamide (DMAc), xylene and toluene were purified by distillation under reduced pressure over calcium hydride and stored over $4 \AA$ molecular sieves.

\section{Measurements}

The ${ }^{1} \mathrm{H}$ NMR and ${ }^{13} \mathrm{C}$ NMR spectra were recorded on a Bruker 500 spectrometer (Bruker BioSpin Corporation, Billerica, MA, USA) with tetramethylsilane as internal standard, dimethyl sulfoxide (DMSO- $\left.\mathrm{d}_{6}\right), \mathrm{CDCl}_{3}$ or $\mathrm{CF}_{3} \mathrm{COOD}$ as a solvent. Elemental analyses were performed with Perkin Elmer 2400 CHN analyzer (Perkin Elmer Corporation, Waltham, MA, USA). Inherent viscosities $\left(\eta_{\text {inh }}\right)$ were obtained at a $0.5-\mathrm{g} \mathrm{dl}^{-1}$ concentration of polyamide acid solutions with an Ubbelohde viscometer at $25^{\circ} \mathrm{C}$. Gel permeation chromatograms were obtained on a Waters 410 instrument (Waters Corporation, Milford, MA, USA) with tetrahydrofuran as an eluent at a flow rate of $1 \mathrm{ml} \mathrm{min}^{-1}$ using polystyrene as a standard. Fourier transform infrared spectra were measured using a Bruker Vector 22 spectrometer. $T_{\mathrm{g}} \mathrm{s}$ and melting points were determined on a TA Q-100 thermal analyzer (TA Corporation, New Castle, DE, USA) under nitrogen atmosphere at a heating rate of $10{ }^{\circ} \mathrm{Cmin}^{-1}$. Thermo gravimetric analysis (TGA) was obtained at a heating rate of $10^{\circ} \mathrm{C} \mathrm{min}^{-1}$ in air or nitrogen atmosphere with a Perkin-Elmer (Pyris 1) thermogravimetric analyzer. Dynamic mechanical analysis (DMA) was performed on thin film specimen (ca. $4 \times 0.5 \times 0.008 \mathrm{~cm}^{3}$ ) on a TA instrument DMA RSA $\Pi$ at a heating rate of $5^{\circ} \mathrm{Cmin}^{-1}$ and at a load frequency of $1 \mathrm{~Hz}$ under nitrogen atmosphere. The peak on the loss modulus curve as a function of temperature was regarded as the $T_{\mathrm{g}}$ value of the film. Ultraviolet-Visible (UV-Vis) spectra of the films were recorded on a UV-Vis 2501 spectrometer (Shimadzu Corporation, Kyoto, Japan). Mechanical properties of the films were measured with a Shimadzu AG-I tensile apparatus (Shimadzu Corporation) at a crossed speed of $8 \mathrm{~mm} \mathrm{~min}^{-1}$ on the strips of approximate $12-18 \mu \mathrm{m}$ thickness and $0.3 \mathrm{~cm}$ width with a 4 -cm gauge length. The SEM measurements were performed on a Shimadzu SSX-550 microscope. The birefringence of the polymer film, at the $650-\mathrm{nm}$ wavelength, was determined from coupling angles of TE (transverse electric) of TM (transverse magnetic) optical guided modes with a gadolinium gallium garnet prism. The crystallization of the films was characterized with a Rigaku Wide-angle X-ray diffractometer (Rigaku Corporation, Tokyo, Japan) (D/max rA, using Cu Ka radiation at wavelength $\lambda=1.541 \mathrm{E})$. The dielectric constants of the polymer films (diameter $13 \mathrm{~mm}$ and thickness $0.5 \mathrm{~mm}$, prepared by compression molding, and then coated with silver by a vacuum evaporation method) were obtained using an HP 4192A LF impedance gain-phase analyzer (HP Corporation, Hélette, French) with an HP-6047C. The polarizability and dipole moments of the model compounds were calculated using WinMOPAC 3.0 software (Fujitsu Laboratories, Kanagawa, Japan). CNDO/S method and MOS-F program (Fujitsu Laboratories) were chosen after the geometry optimization by AM1 method in MOPAC 2000 program.

\section{Photosensitivity}

A 1.2- $\mu \mathrm{m}$-thick photosensitive polymer film was prepared by the dissolution of HBPI in DMAc, followed by spin-coating on a silicon wafer and then prebaked at $120^{\circ} \mathrm{C}$ for $1 \mathrm{~h}$. This film was exposed to $365 \mathrm{~nm}$ (i-line) using a filtered super high-pressure mercury lamp, and then developed in a mixture of DMAc/acetone (9/1, v/v) for $1 \mathrm{~min}$ and rinsed with ethanol. A characteristic photosensitive curve was obtained by the plotting of a normalized film thickness against the exposure dose $\left(\mathrm{mJ} \mathrm{cm}^{-2}\right)$. Film thickness on silicon wafer was measured by a Veeco Instrument Dektak ${ }^{3}$ surface profiler. Image-wise exposure through a mask was carried out in contact-printing mode.

\section{Monomer synthesis}

Synthesis of 1,3,5-tri(4-fluorobenzoyl)benzene (TFBB). A 1000-ml three-necked flask equipped with a mechanical stirrer, a thermometer, a $\mathrm{N}_{2}$ gas inlet and a water condenser was placed $\left(\mathrm{AlCl}_{3}(80.00 \mathrm{~g}, 0.600 \mathrm{~mol})\right.$ and fluorobenzene $(113 \mathrm{ml}, 1.200 \mathrm{~mol}))$. The mixture was cooled to $5^{\circ} \mathrm{C}$, and then a solution of $1,3,5$-benzenetricarbonyl trichloride $(26.55 \mathrm{~g}, 0.100 \mathrm{~mol})$ in $100 \mathrm{ml}$ of fluorobenzene was added through a dropping funnel and kept the temperature below $10^{\circ} \mathrm{C}$ for $1 \mathrm{~h}$. After the addition, the mixture was heated with stirring at $83^{\circ} \mathrm{C}$ for $8 \mathrm{~h}$. The solution was poured into a large quantity of ice water (about $1000 \mathrm{ml}$ ) with a few drops of $\mathrm{HCl}$. The resulting precipitate was filtered off, washed with water and dried in a vacuum oven at $80^{\circ} \mathrm{C}$. Pure product was obtained by recrystallization in acetone. Yield: $42.15 \mathrm{~g}$ (95\%). m.p. (DSC): 187-188 ${ }^{\circ} \mathrm{C}$. IR ( $\mathrm{KBr}$, powder, $\left.\mathrm{cm}^{-1}\right): 1662(\mathrm{C}=\mathrm{O}), 1217$ and $1094(\mathrm{C}-\mathrm{F}) .{ }^{1} \mathrm{H}$ NMR (500 MHz, DMSO-d 6 , p.p.m.): 8.32 (s, 3H), 8.0 (d, 6H), 7.5 (d, 6H).

Synthesis of (TABB). A 250-ml three-necked flask equipped with a mechanical stirrer, a thermometer, a $\mathrm{N}_{2}$ gas inlet, a Dean-Stark trap and a water condenser was placed (TFBB $(4.44 \mathrm{~g}, 0.010 \mathrm{~mol})$ and 3-aminophenol $(5.45 \mathrm{~g}, 0.050 \mathrm{~mol})$ ) in DMF $(50 \mathrm{ml})$ and toluene $(20 \mathrm{ml})$. Then $\mathrm{K}_{2} \mathrm{CO}_{3}(7.59 \mathrm{~g}, 0.055 \mathrm{~mol})$ was added to the mixture, and the reaction mixture was heated to $130^{\circ} \mathrm{C}$ for $10 \mathrm{~h}$ with continuous stirring. The generated water was removed from the reaction mixture by azeotropic distillation. The reaction temperature was raised to $151{ }^{\circ} \mathrm{C}$ by removing toluene, and kept at the same temperature for $15 \mathrm{~h}$. The mixture was allowed to cool and precipitated in water as a solid, which was 
isolated by filtration and dried in a vacuum oven at $40^{\circ} \mathrm{C}$. Recrystallization from ethanol afforded red product. Yield: $6.41 \mathrm{~g}(90 \%) ;$ m.p. (DSC): $102-105^{\circ} \mathrm{C}$. IR $\left(\mathrm{KBr}\right.$, powder, $\left.\mathrm{cm}^{-1}\right)$ : 3451 and $3369(\mathrm{~N}-\mathrm{H}), 1652(\mathrm{C}=\mathrm{O}) .{ }^{1} \mathrm{H}$ NMR $\left(500 \mathrm{MHz}, \mathrm{CDCl}_{3}\right.$, p.p.m.): 8.32 (s, 3H), $7.82(\mathrm{~d}, 6 \mathrm{H}), 7.16$ (t, 3H), 7.05 (d, $6 \mathrm{H}), 6.52(\mathrm{~d}, 3 \mathrm{H}), 6.47(\mathrm{~d}, 3 \mathrm{H}), 6.41(\mathrm{~s}, 3 \mathrm{H}), 3.79(\mathrm{~s}, 6 \mathrm{H}) .{ }^{13} \mathrm{C} \mathrm{NMR}(500 \mathrm{MHz}$, DMSO-d $_{6}$, p.p.m.): $192.9,161.9,155.7,150.8,137.8,133.1,132.6,130.4,130.2$, 117.0, 110.6, 106.8, 105.0. Anal. Calcd for $\mathrm{C}_{45} \mathrm{H}_{33} \mathrm{~N}_{3} \mathrm{O}_{6}$ : C, 75.94; H, 4.67; $\mathrm{N}$ 5.90. Found: C, 75.75; H, 4.59; N, 5.91 .

Synthesis of HBPIs. We used nonideal $\mathrm{A}_{2}+\mathrm{B}_{3}$ polymerization strategy to obtain three novel hyperbranched polyimides. A typical experimental procedure is given below as an example.

A 100-ml three-necked flask equipped with a mechanical stirrer, a thermometer, a $\mathrm{N}_{2}$ gas inlet, a Dean-Stark trap and a water condenser was placed (dianhydride $(1.0 \mathrm{mmol}))$ in DMAc $(10 \mathrm{ml})$. Then TABB $(0.5 \mathrm{mmol})$ in DMAc $(10 \mathrm{ml})$ was added dropwise to the dianhydride solution through a syringe over 3 h. 2,6-Dimethylaniline $(0.6 \mathrm{mmol})$ was added to the mixture $4 \mathrm{~h}$ later, and the reaction was further conducted in a dark cabinet for $24 \mathrm{~h}$ at room temperature to afford an anhydride-terminated PAA solution. Chemical imidization was carried out via the addition of triethylamine ( $1 \mathrm{~g})$ and acetic anhydride $(3 \mathrm{~g})$ into the PAA solution at room temperature overnight. The resulting homogeneous polyimide solution was poured into methanol to give a white precipitate, which was collected by filtration, washed thoroughly with methanol and dried under vacuum at $80^{\circ} \mathrm{C}$ for $24 \mathrm{~h}$.

HBPI-1: IR (KBr, powder, $\left.\mathrm{cm}^{-1}\right): 3068$ ( $-\mathrm{CH}_{3}$ stretching), 1785 and 1727 $(\mathrm{C}=\mathrm{O}$ stretching $), 1665(\mathrm{C}=\mathrm{O}), 1373(\mathrm{C}-\mathrm{N}-\mathrm{C}$ stretching $), 1141 \quad\left(-\mathrm{CF}_{3}\right.$ stretching). ${ }^{1} \mathrm{H}$ NMR $\left(500 \mathrm{MHz}, \mathrm{CF}_{3} \mathrm{COOD}\right.$, p.p.m.): 8.41 (s, $\left.1 \mathrm{H}\right), 8.26-8.28$ (d, $1 \mathrm{H}), 8.02-8.05(\mathrm{~m}, 4 \mathrm{H}), 7.66(\mathrm{~s}, 1 \mathrm{H}), 7.51-7.53(\mathrm{~d}, 1 \mathrm{H}), 7.02-7.27(\mathrm{~m}$, 6H), 6.99-7.00 (d, 1H), 2.10 (s, 3H). ${ }^{13} \mathrm{C}$ NMR $\left(500 \mathrm{MHz}, \mathrm{CF}_{3} \mathrm{COOD}\right.$, p.p.m.): 201.3, 171.7, 166.1, 158.9, 143.5, 140.9, 140.1, 136.3, 134.8, 134.3, 133.8, 132.8, $131.6,129.5,128.9,127.5,126.4,125.7,124.7,124.2,120.7,120.2,114.6,109.2$, 107.7, 68.4, 19.0. Anal. Calcd: C, 65.80; H, 3.16; N, 3.60. Found: C, 65.95; $\mathrm{H}, 3.31 ; \mathrm{N}, 3.26$

HBPI-2: IR ( $\mathrm{KBr}$, powder, $\left.\mathrm{cm}^{-1}\right): 3070\left(-\mathrm{CH}_{3}\right.$ stretching), 1782 and 1728 $(\mathrm{C}=\mathrm{O}$ stretching $), \quad 1666(\mathrm{C}=\mathrm{O}), \quad 1373$ (C-N-C stretching). ${ }^{1} \mathrm{H} \quad \mathrm{NMR}$ (500 MHz, $\mathrm{CF}_{3} \mathrm{COOD}$, p.p.m.): 8.66-8.69 (m, 2H), 8.44 (s, 2H), 8.14-8.19 $(\mathrm{m}, 2 \mathrm{H}), 7.79(\mathrm{~s}, 2 \mathrm{H}), 7.47-7.50(\mathrm{~m}, 6 \mathrm{H}), 2.07(\mathrm{~s}, 3 \mathrm{H}) .{ }^{13} \mathrm{C} \mathrm{NMR}(500 \mathrm{MHz}$, $\mathrm{CF}_{3} \mathrm{COOD}$, p.p.m.): 201.7, 171.6, 166.6, 159.2, 145.2, 141.3, 140.1, 138.0, 136.7, $134.8,134.2,133.6,133.2,131.9,129.2,128.7,128.1,126.7,124.6,122.3,120.9$, 118.8, 114.0, 107.3, 19.7. Anal. Calcd: C, 74.53; H, 3.75; N, 4.35. Found: C, 74.28; H, 3.45; N, 4.36 .

HBPI-3: IR ( $\mathrm{KBr}$, powder, $\left.\mathrm{cm}^{-1}\right): 3075\left(-\mathrm{CH}_{3}\right.$ stretching), 1778 and 1724 $(\mathrm{C}=\mathrm{O}$ stretching $), 1662(\mathrm{C}=\mathrm{O}), 1370(\mathrm{C}-\mathrm{N}-\mathrm{C}$ stretching $), 1244(\mathrm{C}-\mathrm{O}-\mathrm{C}$ stretching). ${ }^{1} \mathrm{H}$ NMR $\left(500 \mathrm{MHz}, \mathrm{CF}_{3} \mathrm{COOD}\right.$, p.p.m.): 8.42 (s, 1H), 7.84-7.88 (m, 4H), 7.35-7.48 (m, 5H), 7.10-7.18 (m, 7H), 6.96-6.99 (d, H), $2.08(\mathrm{~s}, 3 \mathrm{H})$, 1.69 (s, 4H). ${ }^{13} \mathrm{C}$ NMR $\left(500 \mathrm{MHz}, \mathrm{CF}_{3} \mathrm{COOD}\right.$, p.p.m.): 201.1, 172.4, 168.1, $166.0,158.6,154.8,151.2,144.8,140.5,137.3,136.1,134.6,133.5,132.6,131.2$, $129.1,126.3,126.0,125.8,123.9,122.3,121.8,120.3,119.5,118.1,114.6,114.3$, 107.9, 44.9, 32.1, 18.6. Anal. Calcd: C, 76.95; H, 4.54; N, 3.32. Found: C, 76.86; $\mathrm{H}, 4.42 ; \mathrm{N}, 3.23$.

\section{RESULTS AND DISCUSSION}

\section{Monomer synthesis}

TABB were synthesized by the synthetic route outlined in Scheme 1. Reactions were prepared in a two-step. In the first step, TFBB was prepared by Friedel-Crafts acylation of fluorobenzene with 1,3,5benzenetricarbonyl trichloride using $\mathrm{AlCl}_{3}$ as the catalyst. The intermediate was coupled with 3-aminophenol using nucleophilic substitution reaction. All peaks detected in the ${ }^{1} \mathrm{H}$ NMR spectra of amines were consistently assigned (Figure 1). The structures of the amines were also confirmed by IR spectra, elemental analysis and ${ }^{13} \mathrm{C}$ NMR spectroscopy.

\section{Synthesis and characterization of the polyimides}

The method of synthesizing $\left(\mathrm{A}_{2}+\mathrm{B}_{3}\right)$-type hyperbranched polyimide has been described in detail by Fang et al. ${ }^{13}$ The synthesis route was similar to the conventional two-step method for the synthesis of linear polyimides, but many factors affected the polymerization behaviors based on triamines and dianhydrides, such as monomer addition, monomer molar ratios and concentrations. In this work, the addition of TABB to three dianhydrides (6FDA, BTDA and BPADA) with a monomer molar ratio of 1:2 (the molar ratio between the amino and anhydride groups was 3:4), endcapped with 2,6dimethylaniline, and yielded different hyperbranched PAA precursors. Subsequently, the PAAs were chemically converted into polyimides in the presence of acetic anhydride and triethylamine at room temperature (Scheme 2). No gel was formed during polymerization process when monomer concentration as controlled about $5 \%$.

The structures of the HBPIs were confirmed by Fourier transform infrared spectra and ${ }^{1} \mathrm{H}$ NMR spectroscopy. Figure 2 shows the IR spectra of the HBPIs. The absorption peaks at around $1780 \mathrm{~cm}^{-1}$ ( $\mathrm{C}=\mathrm{O}$ asymmetrical stretching $), 1728 \mathrm{~cm}^{-1}(\mathrm{C}=\mathrm{O}$ symmetrical stretching) and $1373 \mathrm{~cm}^{-1}$ (C-N stretching) were the characteristic absorption bands for PI, together with some strong absorption bands in the region of $1100-1300 \mathrm{~cm}^{-1}$ due to the $\mathrm{C}-\mathrm{O}$ and $\mathrm{C}-\mathrm{F}$ stretchings. From the similar results, ${ }^{26,27}$ the chemical imidization method used in these experiments gave fully imidized polyimides. Therefore, the peaks around $1665 \mathrm{~cm}^{-1}$ resulted not from the $\mathrm{C}=\mathrm{O}$ absorption of PAAs but rather from the absorption of the carbonyl groups of TABB. The disappearance of the band around $1859 \mathrm{~cm}^{-1}$, the characteristic band of the $\mathrm{C}=\mathrm{O}$ stretching absorption from the anhydride groups, showed that the end-capping modifications of the terminal anhydride groups of the HBPIs by 2,6-dimethylaniline were achieved completely. ${ }^{13}$

In ${ }^{1} \mathrm{H}$ NMR spectrum of soluble HBPI-1, all aromatic ring protons resonated in the region of 6.9-8.5 p.p.m. (Figure 1). The signal of $\mathrm{H} 1$ in the ortho-positioned at benzophenone group appeared at the farthest downfield region of the spectrum because of the strong

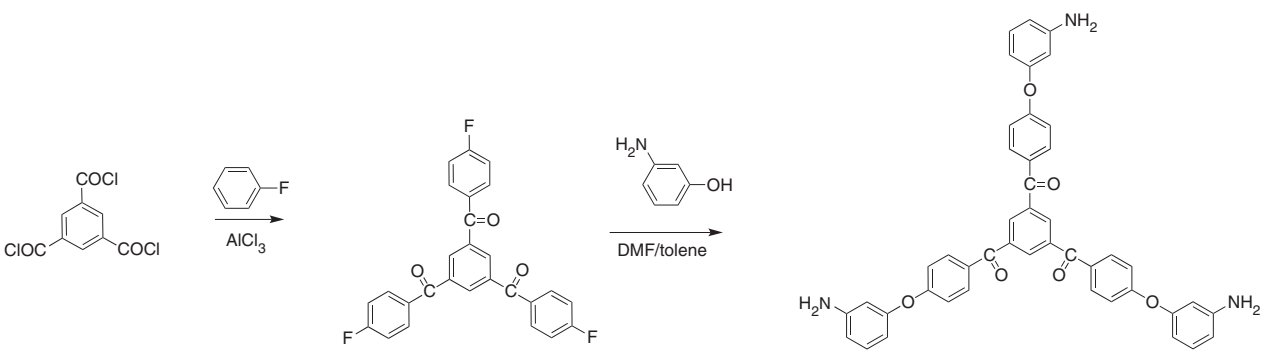

Scheme 1 Synthesis of the triamine 1,3,5-tri(3-aminophenoxy-4'-benzoyl)benzene. 
electron-withdrawing effect of the $\mathrm{C}=\mathrm{O}$ group. The protons $\mathrm{H} 3$ and $\mathrm{H} 5$ shifted to a higher field because of the electron-donating property of aromatic ether. Meanwhile, the methyl group appeared in 2.10 p.p.m. The above results demonstrated that the triamine monomer held a good polymerization activity to form HBPIs, and chemical

a

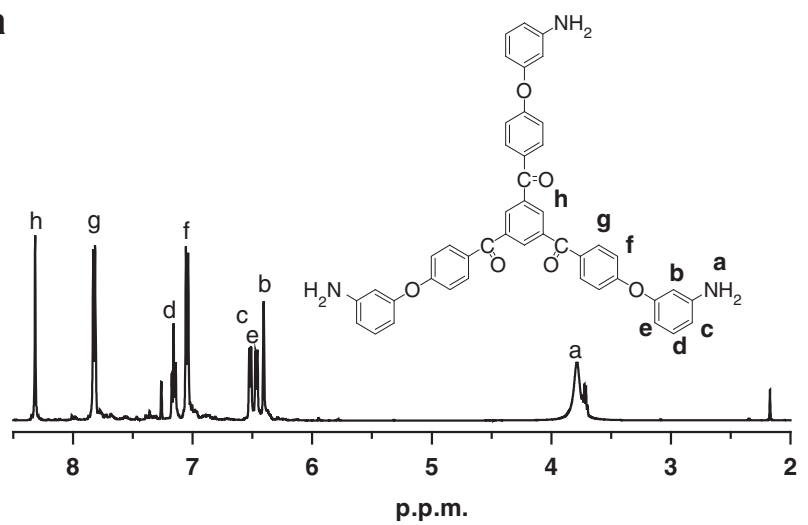

b
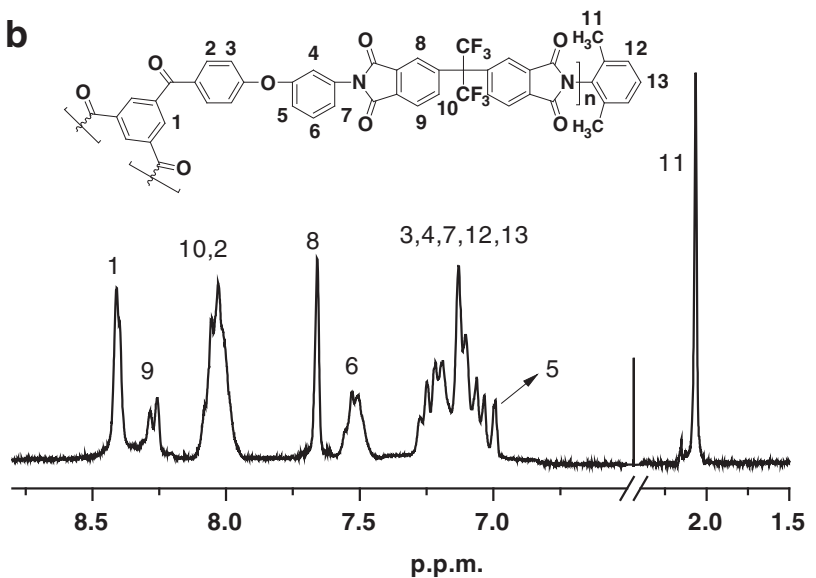

Figure 1 (a) ${ }^{1} \mathrm{H}$ NMR spectra of TABB in $\mathrm{CDCl}_{3}$. (b) ${ }^{1} \mathrm{H}$ NMR spectra of $\mathrm{HBPI}-1$ in $\mathrm{CF}_{3} \mathrm{COOD}$. imidization catalyzed by acetic anhydride and triethylamine could be achieved completely at lower temperature. It is characterized that the molecular weights $\left(M_{\mathrm{w}}\right)$ of the PAA solutions were in the range of $32000-39000$ with the $M_{\mathrm{w}} / M_{\mathrm{n}}$ values of 2.5-2.8, and the intrinsic viscosities of the PAAs were in the range of $0.32-0.43 \mathrm{~g} \mathrm{dl}^{-1}$ (Table 1). Therefore, all prepared polyimides had reasonable molecular weights with broad distributions. The elemental analysis data of the HBPIs showed that the obtained values were reasonable matching with the calculated ones.

The wide-angle $\mathrm{X}$-ray diffraction studies were carried out and showed that the curves of all the PI films were broad and without obvious peak features, which indicate that they are all amorphous (Figure 3). The mean intermolecular distances calculated from the peak maximum for the reflection wide-angle X-ray diffraction patterns for HBPI-1, HBPI-2 and HBPI-3 were 5.84, 5.01 and $5.33 \AA$, respectively. This was reasonable because the HBPIs contained branched structure and non-coplanar unit of monomers that sterically disrupted the chain-packing and inhibited significant chain-chain interactions. The higher intermolecular distance of HBPI-1 could be attributed in part to the presence of the bulky

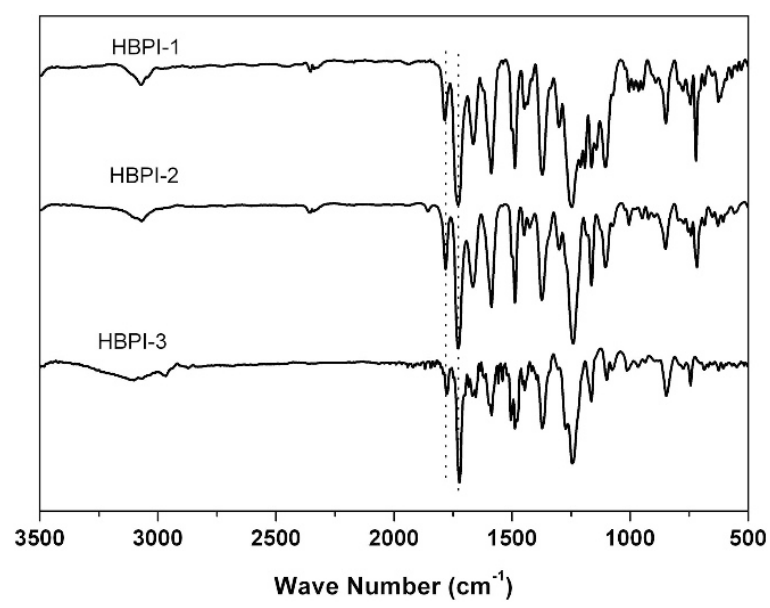

Figure 2 IR spectra of the HBPIs.
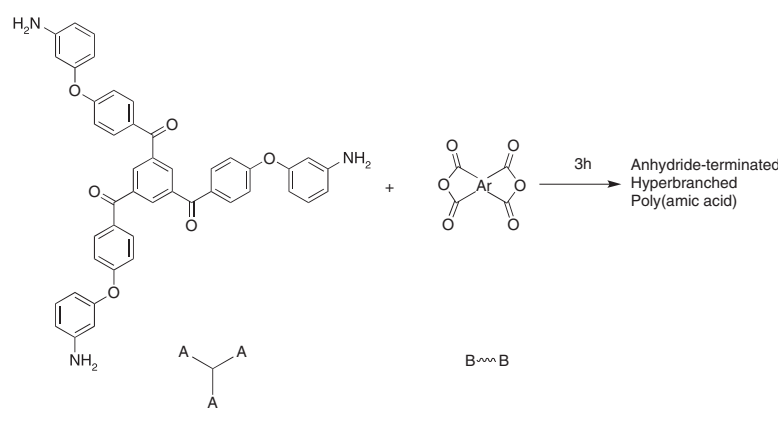

Ar
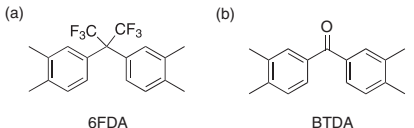

(c)

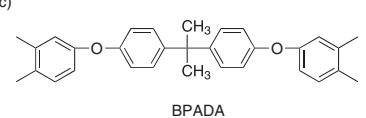

BPADA

Scheme 2 Synthesis of the HBPIs.

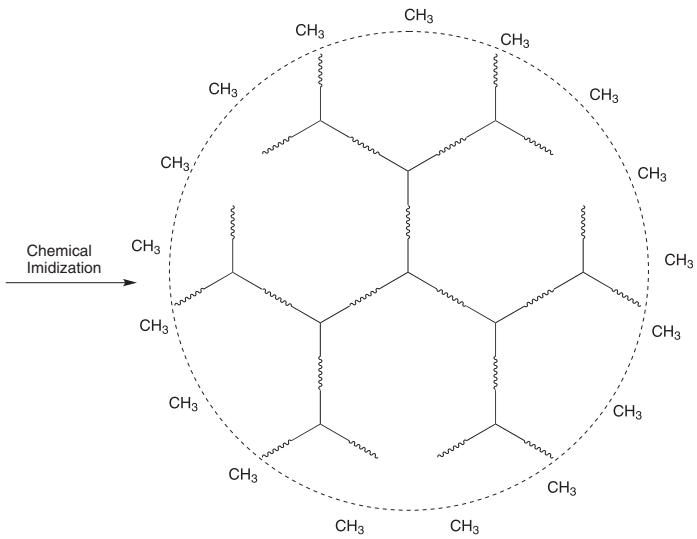


Table 1 Inherent viscosity, GPC data and thermal properties of the HBPIs

\begin{tabular}{|c|c|c|c|c|c|c|c|c|}
\hline \multirow[b]{2}{*}{ Samples } & \multirow[b]{2}{*}{$\begin{array}{c}\eta_{i n h} \\
\left(g d l^{-1}\right)^{a}\end{array}$} & \multicolumn{2}{|c|}{ GPC data } & \multirow[b]{2}{*}{$\begin{array}{c}\mathrm{T}_{g} \\
\left({ }^{\circ} \mathrm{C}\right)^{\mathrm{c}}\end{array}$} & \multirow[b]{2}{*}{$\begin{array}{c}\mathrm{T}_{g} \\
\left({ }^{\circ} \mathrm{C}\right)^{\mathrm{d}}\end{array}$} & \multirow[b]{2}{*}{$\begin{array}{l}\mathrm{T}_{5 \%} \\
\left({ }^{\circ} \mathrm{C}\right)^{\mathrm{e}}\end{array}$} & \multirow[b]{2}{*}{$\begin{array}{l}\mathrm{T}_{10 \%} \\
\left({ }^{\circ} \mathrm{C}\right)^{\mathrm{e}}\end{array}$} & \multirow[b]{2}{*}{$\begin{array}{c}\text { Char } \\
\text { yield }(\%)\end{array}$} \\
\hline & & $\begin{array}{c}\mathrm{M}_{w} \\
\left(\times 10^{4}\right)^{\mathrm{b}}\end{array}$ & $\begin{array}{l}M_{W} \\
W_{n}^{\mathrm{b}}\end{array}$ & & & & & \\
\hline HBPI-1 & 0.43 & 3.9 & 2.5 & 233 & 232 & 515 & 572 & 55.0 \\
\hline HBPI-2 & 0.32 & 3.1 & 2.7 & 238 & 215 & 525 & 581 & 61.0 \\
\hline HBPI-3 & 0.35 & 3.2 & 2.8 & 190 & 180 & 506 & 536 & 56.8 \\
\hline \multicolumn{9}{|c|}{$\begin{array}{l}\text { Abbreviations: GPC, gel permeation chromatogram; HBPI, hyperbranched polymer. } \\
\text { alnherent viscosity determined with a concentration of } 0.5 \mathrm{gdl}-1 \text { in DMAc at } 25^{\circ} \mathrm{C} \pm 0.1^{\circ} \mathrm{C} \text {. } \\
\text { b Relative to polystyrene standard, using tetrahydrofuran as the eluent. } \\
{ }^{\mathrm{c}} T_{\mathrm{g}} \text { measured by DSC at a heating rate of } 10^{\circ} \mathrm{C} \text { min }^{-1} \text {. } \\
{ }^{\mathrm{d}} \mathrm{Tg}_{\mathrm{g}} \text { determined on cured film by DMA at a heating rate of } 5^{\circ} \mathrm{C} \mathrm{min}^{-1} \text {. } \\
{ }^{\mathrm{T}} \text { Temperatures at } 5 \text { and } 10 \% \text { weight loss were recorded by TGA at a heating rate of } \\
10^{\circ} \mathrm{C} \text { min }{ }^{-1} \text { in nitrogen. } \\
\text { fResidual weight retention at } 800^{\circ} \mathrm{C} \text { under nitrogen. }\end{array}$} \\
\hline
\end{tabular}

$\mathrm{CF}_{3}$ group, which resulted in a less dense chain-packing structure. The amorphous phase endows some special features to polyimide, such as high solubility in solvents and lightest color.

\section{Solubility of the polyimides}

The solubility of the HBPIs was evaluated with $10 \mathrm{mg}$ of the polymers in $1 \mathrm{ml}$ of the solvents and the results were summarized in Table 2. All the HBPIs displayed excellent solubilites in common organic solvents, such as DMAc, NMP and DMSO. The 6FDA-based and BPADA-based HBPIs exhibited good solubilities even in common low-boiling point solvents such as tetrahydrofuran, chloroform and acetone. Excellent organosolubilities of the HBPIs can facilitate their film fabrications in optical applications.

\section{Thermal properties of the polyimides}

The thermal properties of the films were examined by means of DSC, DMA and TGA. As shown in Table 1, the incorporation of hyperbranched structure, multiple ether linkages and meta-substituted aromatic rings along the polymer backbone results in the low glass-transitions temperatures $\left(190-238^{\circ} \mathrm{C}\right)$ and no melting points of all obtained films. HBPI-3 had the lowest $T_{\mathrm{g}}$, and it was suggested that the bulky methyl groups and the flexible ether segments in the BPADA units could increase free volume and lower the interaction between polymer chains.

In the DMA profiles of obtained films (Figure 4), $T_{\mathrm{g}}$ s were observed in the range of $180-232^{\circ} \mathrm{C}$ (regarding the peak temperature in the loss modulus curves as the $T_{\mathrm{g}}$ ), which corresponded to the $T_{\mathrm{g}}$ values measured by the DSC technique. The $T_{\mathrm{g}}$ depended on the structure of the dianhydride component and the stiffness of the polymer backbones. The presence of flexible structure (that is, ether bond and methyl groups) in BPADA resulted in the lowest $T_{\mathrm{g}} \mathrm{s}$ of films. HBPI-2 and HBPI-3 films had high storage modulus $(2.1-2.4 \mathrm{GPa})$ at $50^{\circ} \mathrm{C}$ as also shown in Figure 4 , and the values order corresponded to the tensile modulus: HBPI-1<HBPI-3 $<$ HBPI-2. HBPI-1 had the lowest modulus $(1.3 \mathrm{GPa})$ owing to the presence of the bulky $\mathrm{CF}_{3}$ group, which resulted in a less dense chain-packing structure. The storage modulus $\left(E^{\prime}\right)$ of all films declined rapidly at $T_{\mathrm{g}}$ (drop of $E^{\prime}$ at $T_{\mathrm{g}}>10^{3}$ ), suggesting that the obtained films had excellent thermoplasticity and may be suitable for melting process, which were typical values of those amorphous linear polyimides. $^{29}$

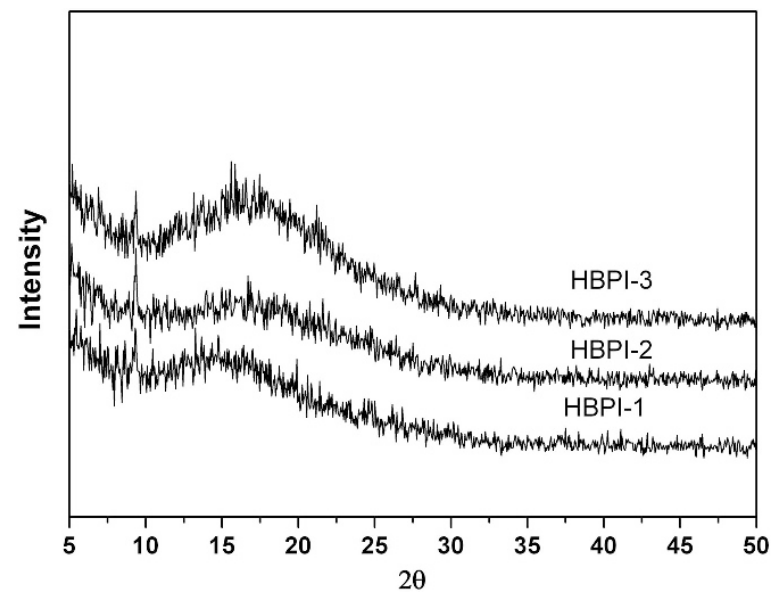

Figure 3 Wide-angle X-ray diffraction pattern of the HBPI films.

\section{Table 2 Solubility of the HBPIs}

Solvents
Tetrahydro-

\begin{tabular}{cccccccccc} 
Samples & $N M P$ & DMAC & DMF & DMSO & furan & Chloroform & Acetone & Ethanol \\
\hline HBPI-1 & ++ & ++ & ++ & ++ & ++ & ++ & ++ & - \\
$\mathrm{HBPI}-2$ & ++ & ++ & ++ & ++ & + & + & - & - \\
$\mathrm{HBPI}-3$ & ++ & ++ & ++ & ++ & ++ & ++ & ++ & -
\end{tabular}

Abbreviations: + , soluble on heating at $100^{\circ} \mathrm{C} ;++$, soluble at room temperature; -, insoluble; DMAc, $N, N$-dimethylacetamide; DMF, $N, N$-dimethylformamide; DMSO, dimethyl sulfoxide; NMP, $\mathrm{N}$-methyl-2-pyrrolidone.

Qualitative solubility was determined as $10 \mathrm{mg}$ of polymer in $1 \mathrm{ml}$ of solvent.

The obtained films also exhibited excellent thermal stabilities, as shown in Figure 4. The TGA curves suggested that the HBPIs were imidized completely. TGA results also showed the films had a 5 and $10 \%$ weight loss temperature in the range of $506-525$ and $536-581^{\circ} \mathrm{C}$ and left more than $55.0 \%$ char yield at $800{ }^{\circ} \mathrm{C}$ in nitrogen, indicating their high thermal and thermooxidative stabilities.

\section{Mechanical properties of the polyimides}

All of the polymers were dissolved in DMAc and cast into a continuous, clear and tough film with a light yellow color. The mechanical properties of the HBPI films are summarized in Supplementary Information. The films showed tensile modulus, elongation at break and tensile strength in the ranges of 1.30-2.45 GPa, 3.0-4.5\% and 37-90 MPa, respectively. HBPI-2, which had the highest imide concentration and the lowest ether concentration, exhibited the highest tensile modulus compared with the HBPIs from BPADA and 6FDA.

\section{Dielectric constants of the polyimides}

The dielectric constants for the HBPIs thin films were evaluated by capacitance method (2.92-3.04) and optical method (2.74-3.09), respectively, as listed in Table 3. The dielectric constants measured by capacitance method $\left(\varepsilon_{\text {cap }}\right)$ were measured at $1 \mathrm{MHz}$ on the thin films and those measured by optical method $\left(\varepsilon_{\text {opt }}\right)$ was calculated from the refractive index of HBPIs thin films in the transverse electric (TE) and transverse magnetic (TM) modes using Maxwell relation $\left(\varepsilon_{\mathrm{opt}} \approx 1.10 n^{2}\right) .{ }^{30-32}$ All HBPIs show lower dielectric constants than 
commercial Kapton films $\left(\varepsilon_{\text {cap }}=3.5\right.$ at $\left.1 \mathrm{kHz}\right) .{ }^{33,34}$ This was attributed to the special hyperbranched structure and the existence of the pendant groups in the center of structure, which has less efficient chain packing and large free volume of the polymer.

Considering the type of dianhydride backbone, the dielectric constant formed lists in the following order: $2>3>1$. The decreased dielectric constants could be explained by the attribution of the bulky $\mathrm{CF}_{3}$ groups and $\mathrm{CH}_{3}$ groups, which had larger free volume of the polymer chain. 6FDA-based HBPI-1 exhibited lowest dielectric
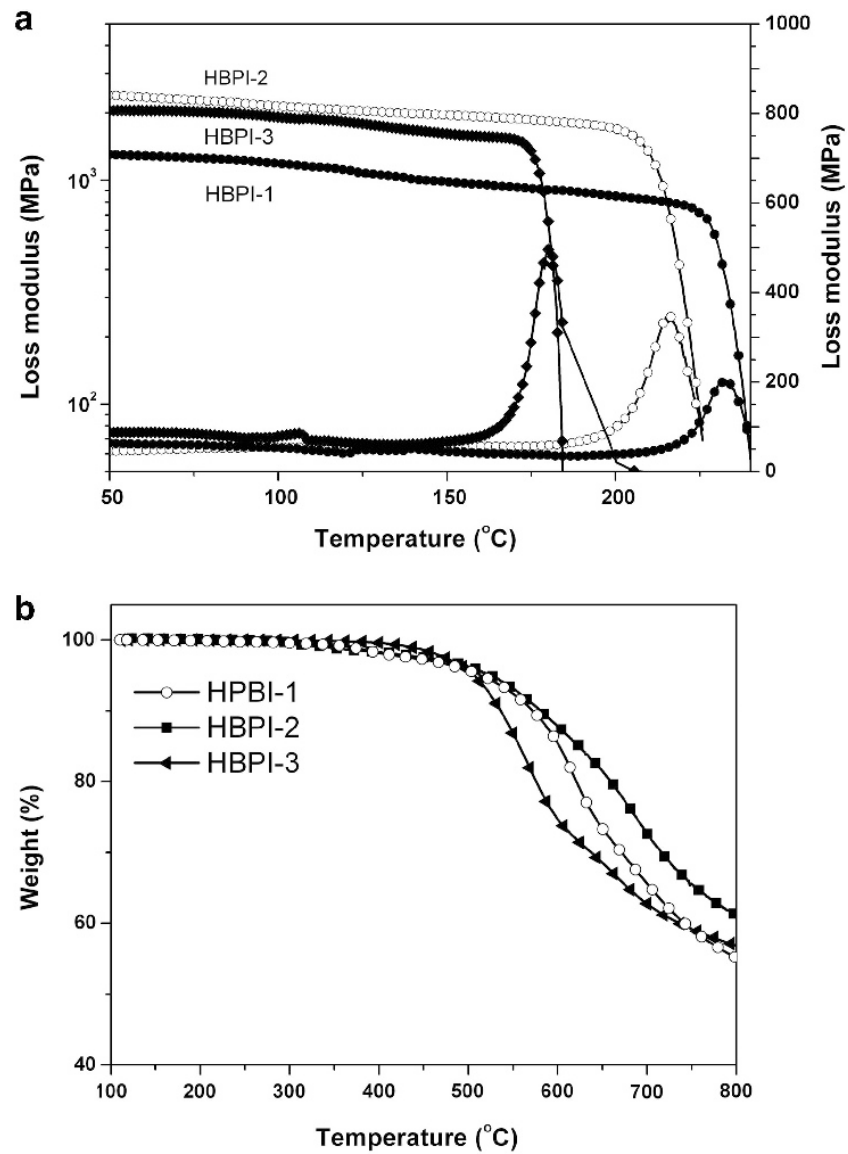

Figure 4 Thermal properties of the HBPI films (a) storage modulus $(E)$ and loss modules $\left(E^{\prime \prime}\right)$ spectra as a function of temperature. (b) TGA curves under nitrogen atmosphere. constants because of the presence of lower polarizability of bulky $\mathrm{CF}_{3}$ groups. ${ }^{35}$ The highest dielectric constant of HBPI-2 value is attributed to the presence of high polar sulfur bridge $(\mathrm{C}=\mathrm{O})$ in polymer chains.

\section{Optical properties of the polyimides}

The optical properties of the polyimide films were studied using UV-Vis 2501 spectrometer. The absorption spectra are displayed in Figure 5 and the results are summarized in Table 3 . All the films exhibited high transparency of $82.0-85.3 \%$ and low $\lambda_{0}$ of $342-353 \mathrm{~nm}$. Owing to the highly conjugated aromatic structures and intermolecular charge-transfer complex (CTC) formation of PI, most polyimides between the UV and visible area have strong absorption. However, these HBPIs, which have flexible groups like ether linkage and bulky side groups like $\mathrm{CH}_{3}$ and $\mathrm{CF}_{3}$ groups in the main chain, reduced the intermolecular CTC between alternating electron-donor (diamine) and electron-acceptor (dianhydride) moieties. On the other hand, it has been assumed that the intermolecular packing in HBPI chains is incompact, which prevents CTC formation and may enhance the optical transparency in the visible region. Moreover, $\mathrm{CF}_{3}$ groups can weaken chain-to-chain cohesive force due to lower polarizability of the $\mathrm{C}-\mathrm{F}$ bond. The decrease in intermolecular CTC formation is understandable from the good solubility of these HBPIs in common organic solvents. HBPI-2 had the deepest color, yellowish, and lowest transparency, as a result of the $\mathrm{C}=\mathrm{O}$ group in BTDA that increased the intramolecular CTC effect. The HBPI-2 film exhibited higher modulus at very high temperature, which also indicated that the HBPI-2 molecular chains had stronger interaction than other films.

The average refractive indices $\left(n_{\mathrm{AV}}\right)$ estimated from the $n_{\mathrm{TE}}$ and $n_{\mathrm{TM}}$ values range between 1.6309 and 1.6613 (Table 3). HBPI-1 had the lowest refractive index due to its $\mathrm{CF}_{3}$ groups, which was lower polarizability of the C-F bond. The birefringences $\left(\Delta n=n_{\mathrm{TE}}-n_{\mathrm{TM}}\right)$ of the HBPI films were in the range 0.0026-0.0085, which were lower than those of the linear polyimides. ${ }^{36}$ The fact that $n_{\mathrm{TE}}$ values were slightly higher than the $n_{\mathrm{TM}}$ ones for all HBPI films reflected the preferential chain orientation parallel to the film plane. It is well known that the birefringence of polymers can be affected by chain flexibility and geometry of the repeat units. ${ }^{37}$ For HBPIs, the 'core' molecule, that is, the triamine structure, is expected to define the configuration of the repeat units primarily. The triamine in the repeat unit is nonplanar and asymmetric in geometry. Therefore, it can reduce the orientation of the bonds involved in the polymer backbone and thus greatly reduces the birefringence. Moreover, the $\mathrm{CF}_{3}$ groups and -O- linkages in the dianhydrides also lower the birefringence due

Table 3 Optical properties and dielectric constants of the HBPIs

\begin{tabular}{|c|c|c|c|c|c|c|c|c|}
\hline \multirow[b]{2}{*}{ Samples } & \multicolumn{5}{|c|}{ Optical method } & \multirow[b]{2}{*}{ Capacitance method $\varepsilon_{\text {cap }}(1 \mathrm{MHz})$} & \multirow[b]{2}{*}{$\lambda_{0}(n m)^{f}$} & \multirow[b]{2}{*}{ UV transmittance $(\%)^{\mathrm{g}}$} \\
\hline & $\mathrm{n}_{T E}{ }^{\mathrm{a}}$ & $\mathrm{n}_{T M}{ }^{\mathrm{b}}$ & $\mathrm{n}_{A V}{ }^{\mathrm{c}}$ & $\Delta \mathrm{n}^{\mathrm{d}}$ & $\varepsilon_{o p t}^{\mathrm{e}}$ & & & \\
\hline HBPI-1 & 1.6318 & 1.6292 & 1.6309 & 0.0026 & 2.92 & 2.74 & 342 & 85.3 \\
\hline HBPI-2 & 1.6641 & 1.6556 & 1.6613 & 0.0085 & 3.04 & 3.09 & 353 & 82.0 \\
\hline HBPI-3 & 1.6504 & 1.6444 & 1.6484 & 0.0061 & 2.99 & 2.95 & 351 & 83.3 \\
\hline
\end{tabular}

an-plane refractive index at $650 \mathrm{~nm}: n_{\mathrm{TE}}$.

bout-of-plane refractive index at $650 \mathrm{~nm}: n_{\mathrm{TM}}$.

cAverage refractive index: $n_{A V}=\left(2 n_{T E}+n_{T M}\right) / 3$.

dBirefringence $\Delta n=n_{\mathrm{TE}}-n_{\mathrm{T}}$.

eDielectric constant estimated from the refractive index at $650 \mathrm{~nm}: \varepsilon_{\mathrm{opt}}=1.10 n^{2} \mathrm{AV}$.

${ }^{f}$ Cutoff wavelength defined as the point at which the transmittance becomes less than $1 \%$.

gUV transmittance at $800 \mathrm{~nm}(\%)$. 


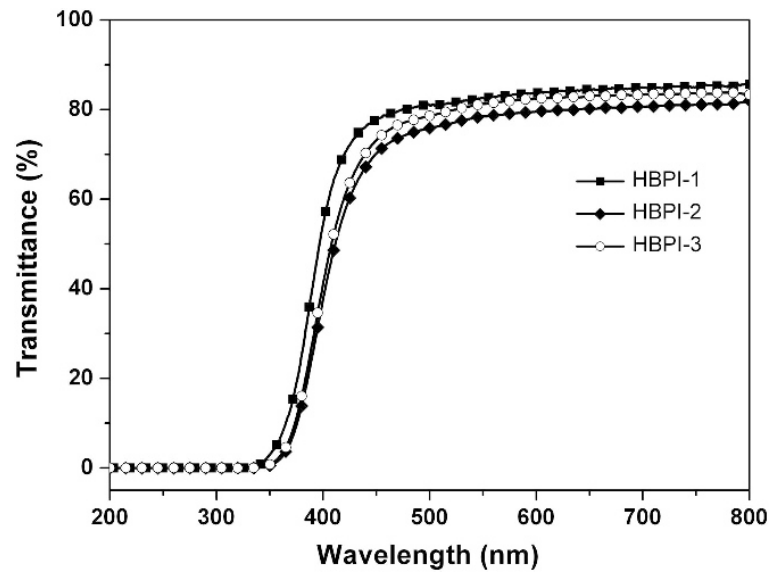

Figure 5 UV-visible spectra of the HBPI films.

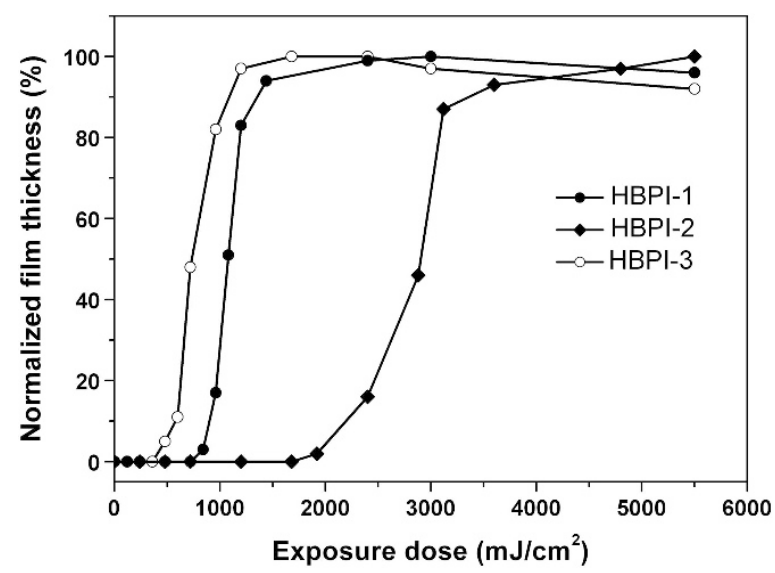

Figure 6 Characteristic photosensitive curve for the HBPIs system.

to the added flexibility of the polymer chains. Based on this point, the HBPIs can challenge the anisotropy and high birefringence of linear polyimides.

\section{Photolithographic evaluation}

The polyimides containing benzophenone groups and alkyl groups were autophotosensitive because of the mechanism that the triplet benzophenone moieties underwent, hydrogen abstraction, from a spatially adjacent ortho-benzyl-positioned alkyl hydrogen of the aniline residues and the successive formation of radical coupling, which yielded a crosslink structure. ${ }^{38,39}$ To determine the photolithographic properties of the PSPIs, these HBPIs were dissolved in DMAc followed by spin-coating on a silicon wafer, and then prebaked at $120^{\circ} \mathrm{C}$ for $1 \mathrm{~h}$ to form thin films around $1.2 \mu \mathrm{m}$ thick. The photosensitivities were evaluated by the irradiation of the films with $365 \mathrm{~nm}$ UV light and by the subsequent determination of the insoluble fraction after development as a function of the log of the exposure dose (Figure 6). The exposure energy needed to attain a 0.5 gel fraction $\left(D_{\mathrm{g}}^{0.5}\right.$, where $D_{\mathrm{g}}$ is the sensitivity) was in the range of $720-2880 \mathrm{~mJ} \mathrm{~cm}^{-2}$ for these autophotosensitive HBPIs. Linear PSPIs with acrylate groups at the side chains and Michler's ketone and triethanolamine as the photosensitizer were reported to have

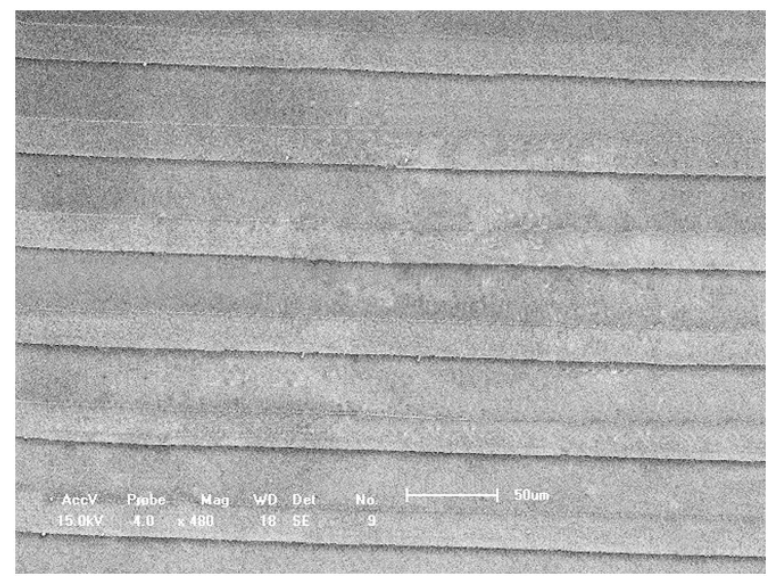

Figure 7 SEM image of the negative pattern in a $1.2-\mu$ m-thick film generated from HBPI-3.

sensitivities in the ranges of $600-1400 \mathrm{~mJ} \mathrm{~cm}^{-2} .40$ The autophotosensitive HBPIs, especially for 6FDA-based and BPADAbased films, showed little change in the sensitivity but without the introduction of small-molecule initiators and small molecules during thermal cyclization, which could reduce the great shrinkage in the patterned films. HBPI-2 has the lowest sensitivity $\left(D_{\mathrm{g}}\right)$ of $2880 \mathrm{~mJ} \mathrm{~cm}^{-2}$, indicating that $\mathrm{C}=\mathrm{O}$ group that increased the electron acceptability of dianhydride caused the CTC effect of both intra- and intermolecular forces, although the content of the benzophenone units were even higher. Moreover, the intermolecular packing in HBPI chains is incompact, which prevents CTC formation and may enhance the quantum yield of crosslinking related to the CT interactions in wholly aromatic PIs. ${ }^{41}$

The patterning images of the photosensitive HBPIs were obtained under a UV exposure dose of $2000 \mathrm{~mJ} \mathrm{~cm} \mathrm{~cm}^{-2}$ in a contact mode with a mask. A mixture of DMAc/acetone $(9 / 1, \mathrm{v} / \mathrm{v})$ was used as the developing solvent and ethanol was used as the rinsing solvent. Figure 7 shows the patterns generated from HBPI-3 as an example. The SEM micrograph demonstrated a highly resolved image with a line width of $20 \mu \mathrm{m}$.

\section{CONCLUSION}

A series of soluble and autophotosensitive hyperbranched polyimides were successfully prepared by condensation of a triamine monomer, $\mathrm{TABB}$, and series of aromatic dianhydride monomers with the endcapping reaction by ortho-alkyl aniline. Their special hyperbranched structures, the presence of pendant groups and aryl ether groups along the polymer backbone of the repeat unit reduced both intramolecular and intermolecular CTC effect. Therefore, the HBPIs showed excellent solubility, excellent thermal stability and low dielectric constant. In addition, HBPI-1 and 3, exhibited excellent optical properties and good photolithographic properties, may be considered as promising processable high-temperature materials for applications in microelectronic and optical devices. Studies designed to investigate their photosensitivity toward UV exposure and to further improve the patterning resolution are in progress.

\section{ACKNOWLEDGEMENTS}

We gratefully acknowledge the financial support from the National Nature Science Foundation of China (National 973 Program No. G2010CB631100). 
1 Kim, Y. H. Hyperbranched polymers 10 years after. J. Polym. Sci. Part A Polym. Chem. 36, 1685-1698 (1998).

2 Voit, B. New developments in hyperbranched polymers. J. Polym. Sci. Part A Polym. Chem. 38, 2505-2525 (2000).

3 Inoue, K. Functional dendrimers, hyperbranched and star polymers. Prog. Polym. Sci. 25, 453-571 (2000)

4 Tomalia, D. A. \& Fréchet, J. M. J. Discovery of dendrimers and dendritic polymers: A brief historical perspective. J. Polym. Sci. Part A Polym. Chem 40, 2719-2728 (2002).

5 Jikei, M. \& Kakimoto, M. Hyperbranched polymers: a promising new class of materials. Prog. Polym. Sci. 26, 1233-1285 (2001).

$6 \mathrm{Kim}$, Y. H. \& Webster, O. W. Water soluble hyperbranched polyphenylene: 'a unimolecular micelle? J. Am. Chem. Soc. 112, 4592-4593 (1990).

7 Zhang, Y., Wang, L., Wada, T. \& Sasabe, H. One-pot synthesis of a new hyperbranched polyester containing 3,6-di-acceptor-substituted carbazole chromophores for nonlinear optics. Macromol. Chem. Phys. 197, 667-676 (1996).

8 Tajbakhsh, A., Moratti, S. C., Koch, A. \& Warner, M. Hyperbranched architectures for NLO polymers. Mol. Cryst. Liq. Cryst. 356, 175-183 (2001).

9 Pitois, C., Wiesmann, D., Lindgren, M. \& Hult, A. Functionalized fluorinated hyperbranched polymers for optical waveguide applications. Adv. Mater. 13, $1483-1484$ (2001)

10 Lee, J. H. \& Lee, K. S. Synthesis and characterization of hyperbranched polymer for second-order nonlinear optics. Mol. Cryst. Liq. Cryst. 371, 341-344 (2001).

11 Nguyen, C., Hawker, C. J., Miller, R. D., Huang, E., Hedrick, J. L., Gauderon, R. \& Hilborn, J. G. Hyperbranched polyesters as nanoporosity templating agents for organosilicates. Macromolecules 33, 4281-4284 (2000).

12 Sun, Q. H., Lam, J. W. Y., Xu, K. T., Xu, H. Y., Cha, J. A. K., Wong, P. C. L., Wen, G. H., Zhang, X. X., Jing, X. B., Wang, F. S. \& Tang, B. Z. Nanocluster-containing mesoporous magnetoceramics from hyperbranched organometallic polymer precursors. Chem. Mater. 12, 2617-2624 (2000).

13 Fang, J., Kita, H. \& Okamoto, K. Hyperbranched polyimides for gas separation applications. 1. Synthesis and characterization. Macromolecules 33, 4639-4646 (2000).

14 Voit, B., Eigner, M., Estel, K., Wenzel, C. \& Bartha, J. W. Labile hyperbranched polymers used as nanopore-forming agents in polymeric dielectrica. Macromol. Symp. 177, 147-154 (2002).

15 Bai, F. L., Zheng, M., Lin, T., Yang, J. L., He, Q. G., Li, Y. L. \& Zhu, D. B. The new approaches to light emitting conjugated polymers-alternating copolymers with hole transport chromophores and hyperbranched polymers. Synth. Met. 119, 179-180 (2001).

16 Dai, L. M., Winkler, B., Dong, L. M., Tong, L. \& Mau, A. W. H. Conjugated polymers for light-emitting applications. Adv. Mater. 13, 915-925 (2001).

17 Duan, L., Qiu, Y., He, Q. G., Bai, F. L., Wang, L. D. \& Hong, X. Y. A novel hyperbranched conjugated polymer for electroluminescence application. Synth. Met 124, 373-377 (2001).

18 He, Q. G., Bai, F. L., Yang, J. L., Lin, H. Z., Huang, H. M., Yu, G. \& Li, Y. F. Synthesis and properties of high efficiency light emitting hyperbranched conjugated polymers. Thin Solid Films 417, 183-187 (2002).

19 Xiao, J. J., Inai, Y., Li, L., Hayakawa, T. \& Kaimoto, M. Positive-type alkaline developable photosensitive branched polyamides with low degree of branching and diazonaphthoquinone as a photosensitive compound. Polym. J. 38, 827-834 (2006).

20 Dong, H. C., Zheng, R. H., Lam, J. W. Y., Häussler, M., Qin, A. J. \& Tang, B. Z. A new route to hyperbranched macromolecules: syntheses of photosensitive poly (aroylarylene)s via 1,3,5-regioselective polycyclotrimerization of bis- (aroylacetylene)s. Macromolecules 38, 6382-6391 (2005)

21 Watanabe, Y., Shibasaki, Y., Ando, S. \& Ueda, M. New negative-type photosensitive alkaline-developable semi-aromatic polyimides with low dielectric constants based on poly(amic acid) from aromatic diamine containing adamantyl units and alicyclic dianhydrides, a cross-linker, and a photoacid generator. Polym. J. 37, 270-276 (2005).

22 Sakayori, K., Shibasaki, Y. \& Ueda, M. Synthesis and properties of poly(amic acid)s and polyimides based on $2,2^{\prime}, 6,6^{\prime}$-biphenyltetracarboxylic dianhydride. J. Polym. Sci. Part A Polym. Chem. 44, 6385-6393 (2006).

23 Shin, G. J., Jung, J. C., Chi, J. H., Oh, T. H. \& Kim, J. B. Synthesis and micropatterning properties of a novel base-soluble, positive-working, photosensitive polyimide having an o-nitrobenzyl ether group. J. Polym. Sci. Part A Polym. Chem. 45, 776-788 (2007).

24 Fukukawa, K. \& Ueda, M. Recent progress of photosensitive polyimides. Polym. J. 40, 281-296 (2008)

25 Pfeifer, J. \& Rohde, 0. In Proceedings of Second International Conference on Polyimides: Polyimides-Synthesis, Characterization and Application (ed. Ellenvillen, N. T.) Ch. 7, 130-131 (Society of Plastics Engineers, New York, 1985).

$26 \mathrm{Chen}, \mathrm{H}$. \& Yin, J. Synthesis of autophotosensitive hyperbranched polyimides based on 3,3',4,4'-benzophenonetetracarboxylic dianhydride and 1,3,5-tris-(4-aminophenoxy)benzene via end capping of the terminal anhydride groups by ortho-alkyl aniline J. Polym. Sci. Part A Polym. Chem. 41, 2026-2035 (2003).

27 Higuchi, H., Yamashita, T., Horie, K. \& Mita, I. Photo-cross-linking reaction of benzophenone-containing polyimide and its model compounds. Chem. Mater. 3, 188-194 (1991).

28 St. Clair, A. K. \& Slemp, W. S. Evaluation of colorless polyimide film for thermal control coating applications. SAMPE J 21, 28-33 (1985).

29 Yu, X. H., Zhao, X. G., Liu, C. W., Bai, Z. W., Wang, D. M., Dang, G. D., Zhou, H. W. \& Chen, C. H. Synthesis and properties of thermoplastic polyimides with ether and ketone moieties. J. Polym. Sci. Part A Polym. Chem. 48, 2878-2884 (2010).

30 Boses, D., Lee, H., Yoon, D. Y., Swallen, J. D. \& Rabolt, J. F. Chain orientation and anisotropies in optical and dielectric properties in thin films of stiff polyimides J. Polym. Sci. Part B Polym. Phys. 30, 1321-1327 (1992).

31 Matsumoto, T. Nonaromatic polyimides derived from cycloaliphatic monomers ${ }^{1}$. Macromolecules 32, 4933-4939 (1999).

32 Watanabe, Y., Shibasaki, Y., Ando, S. \& Ueda, M. Synthesis of semiaromatic polyimides from aromatic diamines containing adamantyl units and alicyclic dianhydrides. $J$. Polym. Sci. Part A Polym. Chem. 42, 144-150 (2004).

33 Maier, G. Low dielectric constant polymers for microelectronics. Prog. Polym. Sci. 26, 3-65 (2001).

34 Banerjee, S., Madhra, M. K. \& Kute, V. Polyimides 6: synthesis, characterization, and comparison of properties of novel fluorinated poly(ether imides). J. Appl. Polym. Sci. 93, 821-832 (2004)

35 Simpson, J. O. \& St. Clair, A. K. Fundamental insight on developing low dielectric constant polyimides. Thin Solid Films 308-309, 480-485 (1997).

36 Kim, Y. M., Lim, E., Kang, I.-N., Jung, B.-J., Lee, J., Koo, B. W., Do, L.-M. \& Shim, H.K. Solution-processable field-effect transistor using a fluorene- and selenophene-based copolymer as an active layer. Macromolecules 39, 4081-4085 (2006).

$37 \mathrm{Ma}$, H., Jen, A. K.-Y. \& Dalton, L. R. Polymer-based optical waveguides: materials, processing, and devices. Adv. Mater. 14, 1339-1365 (2002).

38 Hasegawa, M. \& Horie, K. Photophysics, photochemistry, and optical properties of polyimides. Prog. Polym. Sci. 26, 259-335 (2001).

39 Lin, A. A., Sastri, V. R., Tesoro, G., Reiser, A. \& Eachus, R. On the cross-linking mechanism of benzophenone-containing polyimides. Macromolecules 21, 1165-1169 (1988).

40 Berrada, M., Carriere, F., Coutin, B., Monjol, P. \& Sekiguchi, H. Novel negative-type soluble photosensitive polyimides: synthesis and characterization. Chem. Mater. 8, 1029-1034 (1996).

41 Jin, Q., Yamashita, T. \& Horie, K. Polyimides with alicyclic diamines. II. hydrogen abstraction and photocrosslinking reactions of benzophenone-type polyimides. J. Polym. Sci. Part A Polym. Chem. 32, 503-511 (1994).

Supplementary Information accompanies the paper on Polymer Journal website (http://www.nature.com/pj) 